Интернет-журнал «Науковедение» ISSN 2223-5167 http://naukovedenie.ru/

Выпуск 6 (25) 2014 ноябрь - декабрь http://naukovedenie.ru/index.php?p=issue-6-14

URL статьи: http://naukovedenie.ru/PDF/109EVN614.pdf

DOI: 10.15862/109EVN614 (http://dx.doi.org/10.15862/109EVN614)

\title{
УКД 338.24.01
}

Красоченкова Наталья Петровна

ФГОБУ ВПО «Финансовый университет при Правительстве Российской Федерации» Россия, Москва ${ }^{1}$ Доцент кафедры «Стратегический и антикризисный менеджмент» Кандидат экономических наук E-mail: stas13071@ yandex.ru

\section{Методологические аспекты концепции формирования национальной инновационной среды}


Аннотация. В статье представлены основы формирования оригинальной научной концепции. Автором представлены анализ категориального аппарата теории формирования национальной инновационной среды и собственная точка зрения, согласно которой методология есть совокупность общих принципов, методов и форм, которые используются в исследовании определенной научной области. Результатом управления национальной инновационной среды является уровень инновационной активности. Формирование методологии исследования включает следующие этапы: определение объекта и субъекта управления; выбор соответствующего подхода к проведению исследования; разработка методологических принципов, конкретизирующих подход. В основу авторской концепции формирования национальной инновационной среды положены как существующие методологические принципы, так и впервые предлагаемые. В первой группе представлены такие принципы, как иерархичность, интеграция, моделируемость, целенаправленность, сочетание централизации и децентрализации, расширение границ социально-экономических систем, непрерывность во времени по фазам жизненного цикла инноваций. Системные принципы формирования национальной инновационной среды дополнены следующими: принцип упорядоченности, принцип своевременной коммуникативности, принцип стратегической направленности. Автор при построении научной концепции формирования национальной инновационной среды использовал системный, диалектический общеметодологических подходов и основополагающие принципы теории хаоса.

Ключевые слова: методология; национальная инновационная среда; система; принцип; подход; научная концепция; инновационная система.

Ссылка для цитирования этой статьи:

Красоченкова Н.П. Методологические аспекты концепции формирования национальной инновационной среды // Интернет-журнал «НАУКОВЕДЕНИЕ» 2014. № 6 http://naukovedenie.ru/PDF/109EVN614.pdf (доступ свободный). Загл. с экрана. Яз. рус., англ. DOI: 10.15862/109EVN614 
Множество сложившихся подходов в методологии и теории управления требует определения ключевых методологических принципов исследования национальной инновационной среды. Необходимость данного шага обусловлена в настоящее время изменением тенденций и трендов развития социально - экономических систем в условиях глобализации экономики, изменения полярности мира. Кроме того, основой перехода от индустриальной к постиндустриальной стадии общественного развития характеризуется сменой технологической платформы, для которой характерно то, что информационные технологии, интернет и современная техника внесли значительные изменения во все сферы жизни людей. Число пользователей компьютером сильно возросло во всех странах, например, $90 \%$ взрослого населения в Люксембурге, Нидерландах и 60\% странах Северной Европы. В России уже около половины работников обладает достаточными компьютерными навыками ${ }^{2}$. Данная тенденция отражается на развитии всех стран, регионов и городов и, в конечном счете, на содержании и функциях национальной инновационной среды. В связи с этим, построение логики и методологии разработки целостной системы формирования национальной инновационной среды с учетом изменений, происходящих во внешней и внутренней средах, является актуальной научной задачей.

Основу исследования составляет системный подход, выступающий в качестве научного инструмента мышления, изучения и преобразования окружающей действительности и моделирования на ее основе взаимодействующих систем, подсистем, элементов и процессов, определения их целей и закономерностей развития, ключевых факторов, влияющих на их эффективность ${ }^{3}$

Методология формирования национальной инновационной среды реализуется:

- $\quad$ в определении объекта (- ов) и субъекта (- ов) управления;

- $\quad$ выборе соответствующего (- их) подхода (- ов) к проведению исследования;

- $\quad$ разработке методологических принципов, конкретизирующих подход.

Понятие методологии научного исследования в настоящее время исследователями трактуется неоднозначно.

Коротков Э. М считает, что методология научного исследования рассматривается в виде логической организации деятельности человека, содержание которой состоит в определении цели, предмета исследования, ориентиров и подходов его проведения, выборе методов и средств, определяющих желаемый результат ${ }^{4}$.

В.Штофф под методологией подразумевает научную дисциплину ${ }^{5}$.

Ельчанинов В. А. утверждает, что методология это система общих основополагающих идей и принципов, которых руководствуется ученый в своей познавательной деятельности 6 .

Автор с позиций системного подхода придерживается в ходе исследования национальной инновационной среды наиболее распространенной точки зрения о том, что

\footnotetext{
2 Доклад ОЭСР «Measuring the Digital Economy A New Perspective»/ http://www.oecd.org/russia/sales.htm. Дата обращения - 08.12.2014

${ }^{3}$ Маленков, Ю. А. Современный менеджмент: пособие / Ю.А. Маленков.- М.: ЗАО Изд. «ЭКОНОМИКА», 2010. 439 c.

${ }^{4}$ Коротков, Э. М. Исследование систем управления /Э. М. Коротков. - М.: ДеКА, 2000. - 228 с.

${ }^{5}$ Штофф, В. А. Проблемы методологии научного познания/ В.А. Штофф. - М.: Высшая школа, 1978. - 271 с. ;Бор, М. З. Основы экономических исследований. Логика, методология, организация, методика / М. 3. Бор. - М.: ДИС, 1998. -79 с.

${ }_{6}^{6}$ Ельчанинов, В. А. Методологические проблемы исторической науки: учебное пособие / В. А. Ельчанинов. Барнаул: Алт. гос. ун-т, 1990. - 118 с.
} 
методология есть совокупность общих принципов, методов и форм, которые используются в исследовании определенной научной области ${ }^{7}$.

Система национальной инновационной среды включает объект и субъект управления. В качестве управляемого объекта здесь выступает национальная инновационная структура, инновационная система и в ее рамках экономические отношения между хозяйствующими субъектами, осуществляющими инновационную деятельность, сотрудники организации, а также информационные потоки, технологии и методы их преобразования.

Субъектом управления формированием национальной инновационной среды выступает интегрированная группа участников инновационной деятельности, представляющая интересы государства, общественности, бизнеса и профессиональной группы - изобретателей. На основе получаемой информации и используя различные методы теории управления, данная группа разрабатывает управляющие воздействия для повышения инновационной активности в стране - концепцию, законодательные и нормативные акты, программы, проекты, мероприятия. Результатом управления национальной инновационной среды является уровень инновационной активности.

Национальная инновационная среда, как сложная социально-экономическая система, развивается согласно законам диалектики в результате внутреннего динамического взаимодействия противоречий внутри нее самой, и тем самым обеспечивая качественное развитие. Противоречия между мыслительным (виртуальным) образом и его практической реализацией, целью и результатом существуют постоянно и потому требуют решения. Постановка целей, определение путей развития системы национальной инновационной среды является разрешением объективного противоречия между сложившимся состоянием системы национальной инновационной среды, ограничениями и перспективами ее развития. Разрешение появившихся противоречий на определенный момент времени не приводит к их полному устранению. Они постоянно и непрерывно возникают в новых условиях и требуют принятия новых соответствующих решений ${ }^{8}$.

Опыт теоретического исследования социально - экономических систем, показывает, что системный подход традиционно заключается в разделении объекта на подсистемы ${ }^{9}$, каждая из которых изучается отдельно вне учета взаимосвязей между другими подсистемами. В результате всегда появляются многочисленные сложные противоречия. Основная причина заключается в том, что между подсистемами противоречия могут возникать не только в свойствах и законах функционирования подсистем, но и в плоскости структуры, организации взаимодействия элементов, определения режимов функционирования в условиях постоянного изменения внешней среды. В теории и практике управления известно множество примеров, когда в результате изменения одного из элементов системы вся система могла оставаться прежней, но и могла меняться и даже разрушаться.

В многочисленной научной литературе в области системного анализа систематизированы актуальные проблемы использования системного подхода в различных

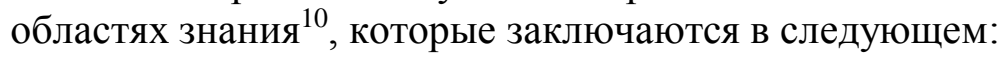

\footnotetext{
${ }^{7}$ Ворожцов, В.П., Москаленко, А.Т. Методологические установки ученого: Природа и функции / В. П. Ворожцов, А.Т. Москаленко. - Новосибирск: Наука, 1986. - 336 с.

${ }^{8}$ Капустина Н.В., Кузнецов Ю.В. Принципы исследования системы управления рисками. Вестник МГТУ, том 13 , N 1, 2010 г. - C. 15-21

${ }^{9}$ Там же - c.8

${ }^{10}$ Блауберг, И. В., Садовский, В.Н., Юдин, Э. Г. Философский принцип системности и системный подход

/И.В.Блауберг, В.Н.Садовский, Э.Г. Юдин // Вопросы философии. - 1978. - № 8.- С. 29 -52, с.52
} 
- идентификация, формализация и описание основных понятий системного подхода;

- $\quad$ характеристика и определение содержания специфических методов системного исследования;

- создание классификаций систем;

- $\quad$ разработка методологии теории управления, расширяющая возможности исследования сложных систем;

- $\quad$ разработка методологии проектирования сложных социально-экономических систем.

В частности, применительно к научной области формирования национальной инновационной среды можно выделить следующие проблемы:

- $\quad$ отсутствие необходимой и достаточной информационной базы, необходимой для анализа, прогнозирования и управления формированием национальной инновационной среды;

- слабая структурированность проблем;

- у увеличение как благоприятных возможностей, так и негативных факторов в национальной инновационной среде, вызванных постоянным и стремительным изменением условий внешней среды в период трансформации технологической платформы;

- отсутствие методических разработок, инструментов, а также адекватных средств, обеспечивающих решение слабоструктурированных проблем, к которым относится национальная инновационная среда;

- $\quad$ отсутствие профессиональных управленческих кадров в области формирования современной национальной инновационной среды, так как многие специалисты с трудом адаптируются на темп современной среды хозяйствования и специфику информационной среды.

В мировой экономической литературе для проведения системного анализа нашли отражение следующие подходы: системно-компонентный, системно-структурный, системнофункциональный ${ }^{11}$. Применительно к национальной инновационной среде их содержание проявляется в следующем:

- $\quad$ системно-компонентный подход применительно к исследованию системы национальной инновационной среды заключается в необходимости выделения ее основных элементов и подсистем, взаимодействие которых обеспечивает качественные свойства, присущие конкретной системе. Выделение основных элементов и подсистем определяются содержанием национальной инновационной среды, решаемыми целями и задачами, а также условиями внешней среды;

- $\quad$ системно-структурный подход предусматривает исследование внутренних связей и взаимодействий между элементами и подсистемами национальной инновационной среды. Структурные свойства национальной инновационной среды обеспечиваются наличием устойчивых взаимосвязей между элементами

\footnotetext{
${ }^{11}$ Акимов, А.А., Гамидов, Г.С., Колосов, В.Г. Системологические основы инноватики/ А.А. Акимов, Г.С. Гамидов, В.Г. Колосов. - СПб.: «Политехника», 2002. - 600 с.,
} 
и подсистемами. Система может обнаружить сложное поведение, однако, некоторые присущие ей свойства остаются при этом неизменными. ${ }^{12}$ Изменение характеристик отдельных элементов системы не сразу ведет к изменению системы. В результате накопления количественных изменений внутри системы под воздействием внешней среды он может произойти, и в результате происходит либо эволюционное, либо революционное развитие;

- $\quad$ системно-функциональный подход предполагает анализ функциональных аспектов отдельных подсистем и элементов системы в их взаимосвязи. Функциональное описание элементов национальной инновационной среды можно представить в виде иерархической структуры, которая по горизонтали содержит координирующие аспекты (согласование функций и компонентов), по вертикали - аспекты субодинации (согласование функций элементов и подсистем), которые определяют специфическое место и характеризует различную значимость каждого из компонентов в функционировании всей национальной инновационной среды в целом.

Комбинирование вышеуказанных подходов к анализу социально - экономических систем позволяет исследовать не только состояние самого объекта исследования, но и взаимодействия, осуществляемые данной системой в процессе развития.

Таким образом, главное требование развития современного развития науки проявляется в необходимости использования единой общенаучной методологии при разработке системного подхода - это использование в качестве методологической основы диалектические законы. Использование системного похода подразумевает главный способ анализа объекта разделение его на подсистемы. Диалектическая основа при проведении научных исследований учитывать разнокачественность, тождество в многозначность сложных социально экономических систем. Внутренняя противоречивость сложной системы согласно законам диалектики является сущностным свойством целого. ${ }^{13}$

Кроме того, многогранность и необычайная сложность общественного развития начала XXI столетия, способного «претерпевать огромное число бифуркаций» (раздвоений), сформировало новую среду в мире. Это связано с тем, что сложные системы недостаточно устойчивы и потому обладают «высокой чувствительностью по отношению к флуктуациям»

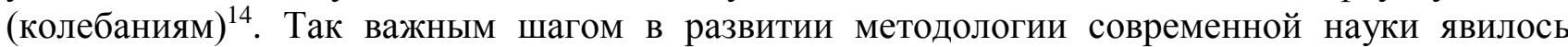
формирование теории хаоса. Теория систем и теория хаоса определяют необходимость рассматривать поведение системы в целом. Социально - экономическая система - это интеграция, и их характер зависит от целого. ${ }^{15}$

Данная особенность является ключевой. При отсутствии сильных возмущений из внешней среды система остается устойчивой неопределенно длительное время, так как отсутствуют условия, побуждающие её к развитию. При нарушении данного порядка возникает большое число решений и бифуркационных явлений, которые побуждают систему к развитию. Развитие проявляется в появлении новых качественных свойств системы, которыми могут быть такие, как: совершенствовании содержания и использования факторов производства, развитии социальных ценностей (материальных и духовных благ), возвышении человеческой личности,

\footnotetext{
${ }^{12}$ Математика и кибернетика в экономике. Словарь-справочник.- М.: «Экономика», 1975.

${ }^{13}$ Кузнецов, Ю.В. Теория организации: учебное пособие / Ю.В. Кузнецов. - СПб.: Изд-во Петерб. Ун-та, 2006. - 158 с.

${ }^{14}$ Кузнецов, Ю.В. Развитие методологии менеджмента / Кузнецов, Ю.В. // Проблемы теории и практики управления. - 1997. - №4. - С. 110.

${ }^{15}$ Кузнецов, Ю.В. Теория организации: учебное пособие / Ю.В. Кузнецов. - СПб.: Изд-во Петерб. Ун-та, 2006. - 158 с.
} 
повышении качества социальных отношений ${ }^{16}$. Инновации являются главным фактором экономического развития ${ }^{17}$. Случайность выступает как конструктивный фактор развития, для которого фундаментальное значение имеет случайности, и, как следствие, - возможности ${ }^{18}$.

При формировании научной концепции формирования национальной инновационной среды необходимо исходить из сложности данного процесса. Данный процесс требует определения содержания теоретической исходной модели системы и разработки принципов взаимодействия ее составных частей. В данном случае составные части рассматриваются совместно, во взаимосвязи и диалектическом единстве, так как раскрытие сущности проблем системы национальной инновационной среды возможно лишь через изучение динамики взаимодействия ее составных частей и внешних условий. Такой подход, в свою очередь, требует уточнения основополагающих системных принципов, отражающих специфику национальной инновационной среды.

Отбор методологических принципов обусловлен необходимостью раскрытия сущности формирования системы национальной инновационной среды, ее функций и характером влияния на национальную экономику в целом и отдельных ее подсистем. В этой связи в основу исследования положены как существующие методологические принципы, так и впервые предлагаемые.

1. Принцип иерархичности требует изучения национальной инновационной среды на микро-, мезо- и макроуровнях. Система национальной инновационной среды представляет собой совокупность взаимосвязанных между собой и структурированных элементов и подсистем на всех уровнях управления. Иерархичность в ней проявляется через инновационную инфраструктуру и заключается в том, что система национальной инновационной среды осуществляет свою деятельность в каждой подсистеме, независимо от количества иерархических уровней и места нахождения подсистемы в иерархии. Главная особенность современной национальной инновационной среды как системы - высокая степень зависимости верхних уровней иерархии от нижних, то есть любое малейшее изменение элемента подсистемы на микроуровне иерархии может привести к кардинальным переменам на макроуровне. Кроме того, важной задачей формирования национальной инновационной среды, является гармонизация её взаимодействия с внешней средой, так как она является основным источником неопределенности и одновременно - развития и это должно находить отражение в постоянной адаптации информационной инфраструктуры к внешней среде.

2. Принцип интеграции означает изучение интегративных свойств и закономерностей систем и их комплексов, раскрытие базисных механизмов интеграции целого. Данный принцип проявляется во взаимосвязи между самими элементами системы национальной инновационной среды. Проблема заключается в том, что система национальной инновационной среды является подсистемой национальной экономики, системы более высшего порядка, и вынуждена функционировать в сложных регулярно изменяющихся социально-экономических отношениях, где постоянно возникают новые флуктуации, требующие гибкого реагирования.

3. Принцип моделируемости подразумевает, что система может быть представлена множеством моделей, отражающих определенную сторону ее сущности. Моделирование процессов формирования национальной инновационной среды дает возможность исследовать определенные свойства при помощи одной или нескольких узкоориентированных моделей. Проблема реализации данного принципа может проявиться в том, что часть исследований,

\footnotetext{
16 Романов, А.А. Экономическое развитие территории / А.А. Романов. - Краснодар: ЮИМ, 2003. -42с.

${ }^{17}$ Иванова, Н. И. Национальные инновационные системы /Н. И. Иванова. - М.: Наука, 2002.- 244 с.

${ }^{18}$ Парнюк, М.А., Причепий, Е.Н., Кизима, В.В. Необходимость и случайность / М.А.Парнюк, Е.Н. Причепий, В.В. Кизима.- Киев: Наук.думка, 1988. - 310 с.-с.109.
} 
посвященных исследованию национальной инновационной среды, могут рассматривать виртуальные модели, которые концептуально могут не успевать отражать реальную действительность, высокую турбулентность внешнего окружения.

4. Принцип целенаправленности, понимаемый как свойство направленности национальной инновационной среды в ходе её реализации на достижение определенной конечной цели, связанной либо с формированием определенного состояния системы, либо с усилением и развитием каких-либо ее качеств. При этом система национальной инновационной среды должна адаптироваться к воздействию внешней среды. Национальная инновационная среда, являясь по определению целенаправленной системой, требует обоснованного выбора общей цели и ее четкой формулировки. На её основе формулируются промежуточные цели. Если они расплывчатые и некорректные, то это может повлечь ошибки в структуре и управлении системой, принятии решений и в результате привести к негативным последствиям и, в худшем случае, - разрушению системы.

5. Принцип сочетания централизации и децентрализации означает, что ситуация, в которой управление исходит лишь из одного центра (полная централизация), считается оправданной при неспособности подсистем самостоятельно противостоять воздействию внешней среды. Чем выше степень децентрализации управления в системе, тем сложнее осуществлять процесс согласования целей одного уровня с общей целью существования и функционирования системы. В децентрализованной системе достижение общей цели возможно при наличии механизма мониторинга, не позволяющего значительно отклоняться от достижения конечной цели. Кроме того, сложность сочетания в системе национальной инновационной среды централизации и децентрализации необходимо разрешить путем разработки государственной концепции формирования национальной инновационной среды с последующей конкретизацией функций управления на нижних иерархических уровнях управления (региона, отрасли, организации).

6. Принцип расширения границ социально-экономических систем предполагает, что постоянно изменяются окружение и условия функционирования социально-экономических систем по таким причинам, например: изменение в деловой среде, расширение групп влияния (стейкхолдеров), создание новых экономических институтов и т.д.. Появление изменений развитие требует использования адекватных подходов для адаптации и расширения границ посредством интеграции в другими субъектами национальной экономики. Особенность современного периода российской экономики заключается в том, что одновременно происходят как развитие и появление новых институтов и механизмов, так и модернизация старых. В первом случае адаптация является ответом на инновации, во втором - на трансформацию действующих институтов, факторов. Реализация данных процессов ведет к расширению границ и внутри, и вне системы. ${ }^{19}$

7. Принцип непрерывности во времени по фазам жизненного цикла инноваций означает непрекращающееся целенаправленное регулирование системы национальной инновационной среды. Поддержку системы национальной инновационной среды необходимо осуществлять постоянно в зависимости от той фазы жизненного цикла, на которой находится инновация, до того периода, когда она превращается в товар. ${ }^{20}$

К общеизвестным методологическим принципам формирования национальной инновационной среды предлагается дополнительно ввести в научный оборот следующие принципы.

\footnotetext{
${ }^{19}$ Филимонова Н.М. Стратегия развития малого предпринимательства в Российской Федерации: монография / Владимир: ВООО ВОИ, 2005. - 250 с.

${ }^{20}$ Там же
} 
8. Принцип упорядоченности действий формирования национальной инновационной среды. Проблема заключается в том, что в случае даже небольших изменений и отклонений нарушается сбалансированность системы, в результате управление ею становится достаточно сложным и может носить спонтанный характер. Необходимы разработка технологий, инструментов, алгоритмов управления с упорядоченными действиями, осуществляемыми в определенной последовательности.

9. Принцип своевременной коммуникативности заключается в своевременной информированности всех элементов и подсистем национальной инновационной среды о возможном ее изменении, а также наличие активной обратной связи. Данный принцип приобретает более актуальное значение при формировании национальной инновационной среды, чем в других подсистемах управления, так как каждая секундная задержка информации может повлечь за собой появление все новых конкурентов и других трудностей. Реализация данного принципа обеспечит свободное движение информации между всеми уровнями и элементами управления формированием национальной инновационной средой.

10. Принцип стратегической направленности заключается в том, что в рамках национальной инновационной среды должна осуществляться не только текущее управление инновационным развитием, но и повышение инновационной активности - основного внутреннего механизма, результатом которого является появление новых инновационных стратегических областей.

Таким образом, формирование по представленной методологии, национальной инновационной среды безусловно сможет повысить инновационную активность в России. 


\section{ЛИТЕРАТУРА}

1. Акимов, А.А. , Гамидов, Г.С., Колосов, В.Г. Системологические основы инноватики/ А.А. Акимов, Г.С. Гамидов, В.Г. Колосов. - СПб.: «Политехника», 2002. $-600 \mathrm{c}$.

2. Акимов, А.А. , Гамидов, Г.С., Колосов, В.Г. Системологические основы инноватики/ А.А. Акимов, Г.С. Гамидов, В.Г. Колосов. - СПб.: «Политехника», 2002. -600 c., c.196.

3. Блауберг, И. В., Садовский, В.Н., Юдин, Э. Г. Философский принцип системности и системный подход /И.В.Блауберг, В.Н.Садовский, Э.Г. Юдин // Вопросы философии. - 1978. - № 8.- С. 29 -52, с.52

4. Бор, М. 3. Основы экономических исследований. Логика, методология, организация, методика / М. З. Бор. - М.: ДИС, 1998. -79 с.

5. Ворожцов, В.П., Москаленко, А.Т. Методологические установки ученого: Природа и функции / В. П. Ворожцов, А.Т. Москаленко. - Новосибирск: Наука, 1986. - 336 с.

6. Гамидов, Г.С.Колосов, В. Г., Османов, Н. О. Основы инноватики и инновационной деятельности: монография / Г.С.Гамидов, В. Г.Колосов, Н. О.Османов. - СПб.: Политехника, 2001. - 323 с., с.174;

7. Гейтс, Б. Бизнес со скоростью мысли / Б. Гейтс. -2-е изд, перераб. и доп. - М.: Эксмо, 2002. - 480 с.

8. Доклад ОЭСР «Measuring the Digital Economy A New Perspective» / http://www.oecd.org/russia/sales.htm. Дата обращения - 08.12.2014

9. Ельчанинов, В. А. Методологические проблемы исторической науки: учебное пособие / В. А. Ельчанинов. - Барнаул: Алт. гос. ун-т, 1990. - 118 с.

10. Иванова, Н. И. Национальные инновационные системы /Н. И. Иванова. - М.: Наука, 2002.- 244 с.

11. Капустина Н.В., Кузнецов Ю.В. Принципы исследования системы управления рисками. Вестник МГТУ, том 13, N 1, 2010 г. - С. 15-21

12. Коротков, Э. М. Исследование систем управления /Э. М. Коротков. - М.: ДеКА, 2000. $-228 \mathrm{c}$.

13. Кузнецов, Ю.В. Развитие методологии менеджмента / Кузнецов, Ю.В. // Проблемы теории и практики управления. - 1997. - №4. - С. 110-114.

14. Кузнецов, Ю.В. Теория организации: учебное пособие / Ю.В. Кузнецов. - СПб.: Изд-во Петерб. Ун-та, 2006. - 158 с.

15. Кузнецов, Ю.В. Теория организации: учебное пособие / Ю.В. Кузнецов. - СПб.: Изд-во Петерб. Ун-та, 2006. - 158 с.

16. Маленков, Ю. А. Современный менеджмент: пособие / Ю.А. Маленков.- М.: ЗАО Изд. «ЭКОНОМИКА», 2010. - 439 с.

17. Математика и кибернетика в экономике. Словарь-справочник.- М.: «Экономика», 1975.

18. Николис,Г.,Пригожин,И. Познание сложного. Введение/ Г.Николис,И. Пригожин. - 2-е изд., пер. с англ. - М.: УРСС, 2003. - 275 с.

19. Парнюк, М.А., Причепий, Е.Н., Кизима, В.В. Необходимость и случайность / М.А.Парнюк, Е.Н. Причепий, В.В. Кизима.- Киев: Наук.думка, 1988. - 310 с.c.109.

20. Прангишвили, И. В., Пащенко, Ф. Ф., Бусыгин, Б. П. Системные законы и закономерности в электродинамике, природе, обществе / И.В.Прангишвили, Ф.Ф.Пащенко,Б. П. Бусыгин. - М.: Наука, 2001. -125 с. 
21. Пригожин, И., Стенгерс, И. Порядок из хаоса: Новый диалог человека с природой / И. Пригожин, И.Стенгерс. М.: Прогресс, 1986. -432 с., с 386

22. Романов, А.А. Экономическое развитие территории / А.А. Романов. - Краснодар: ЮИМ, 2003. -42c.

23. Спицнадель, В. Н. Основы системного анализа: учебное пособие / В. Н. Спицнадель.- СПб.: Бизнесс-пресса, 2000. - 326 с.

24. Федосова Р.Н. Методологические основы управления социальноэкономическими процессами на предприятиях: монография.- Владимир, ВлГТУ, 1996. - $176 \mathrm{c}$.

25. Филимонова Н.М. Стратегия развития малого предпринимательства в Российской Федерации: монография / Н.М. Филимонова. - Владимир: ВООО ВОИ, 2005. - 250 c.

26. Штофф, В. А. Проблемы методологии научного познания/ В.А. Штофф. - М.: Высшая школа, 1978. - 271 с.

Рецензент: Федосова Раиса Николаевна, д.э.н., проф. Генеральный директор ООО «Инновационный социальный центр», г.Камешково, Владимирской области, Россия. 
Krasochenkova Natalia Petrovna

Financial University the government of the Russian Federation

Russia, Moscow

E-mail: stas13071@yandex.ru

\title{
Methodological aspects of the concept of the formation of the national innovation environment
}

\begin{abstract}
The article presents the basis for the formation of the original scientific concept. The author presents the analysis of a categorical theory of the formation of the national innovation environment and its own point of view, according to which the methodology is a set of General principles, methods and forms used in the study of certain scientific field. The result of administration of the national innovation environment is the level of innovation activity. The formation of the research methodology includes the following stages: definition of the object (s) and subject (s) of administration; the appropriate choice (their) approach (s) to conduct research; development of methodological principles, outlining the approach. The author's concept of the formation of the national innovation environment based on existing methodological principles, and for the first time offer. In the first group presents principles such as hierarchy, integration, modelelement, purposefulness, the combination of centralization and decentralization, and the expansion of socioeconomic systems, continuity in time by the phases of the life cycle of innovation. System principles of formation of the national innovation environment supplemented by the following: the principle of order, the principle of timely communication, the principle of strategic focus. The author of building a scientific conception of the national innovation environment used system, dialectical General methodological approaches and fundamental principles of chaos theory.
\end{abstract}

Keywords: methodology; national innovation environment; system; principle; approach; concept; innovation system. 


\section{REFERENCES}

1. Akimov, A.A., Gamidov, G.S., Kolosov, V.G. Sistemologicheskie osnovy innovatiki/ A.A. Akimov, G.S. Gamidov, V.G. Kolosov. - SPb.: «Politekhnika», 2002. - 600 s.

2. Akimov, A.A., Gamidov, G.S., Kolosov, V.G. Sistemologicheskie osnovy innovatiki/ A.A. Akimov, G.S. Gamidov, V.G. Kolosov. - SPb.: «Politekhnika», 2002. - 600 s., s.196.

3. Blauberg, I. V., Sadovskiy, V.N., Yudin, E. G. Filosofskiy printsip sistemnosti i sistemnyy podkhod /I.V.Blauberg, V.N.Sadovskiy, E.G. Yudin // Voprosy filosofii. 1978. - № 8.- S. $29-52$, s.52

4. Bor, M. Z. Osnovy ekonomicheskikh issledovaniy. Logika, metodologiya, organizatsiya, metodika / M. Z. Bor. - M.: DIS, 1998. -79 s.

5. Vorozhtsov, V.P., Moskalenko, A.T. Metodologicheskie ustanovki uchenogo: Priroda i funktsii / V. P. Vorozhtsov, A.T. Moskalenko. - Novosibirsk: Nauka, 1986. - 336 s.

6. Gamidov, G.S.Kolosov, V. G., Osmanov, N. O. Osnovy innovatiki i innovatsionnoy deyatel'nosti: monografiya / G.S.Gamidov, V. G.Kolosov, N. O.Osmanov. - SPb.: Politekhnika, 2001. - 323 s., s.174;

7. Geyts, B. Biznes so skorost'yu mysli / B. Geyts. -2-e izd, pererab. i dop. - M.: Eksmo, 2002. - $480 \mathrm{c}$.

8. Doklad OESR «Measuring the Digital Economy A New Perspective» / http://www.oecd.org/russia/sales.htm. Data obrashcheniya - 08.12.2014

9. El'chaninov, V. A. Metodologicheskie problemy istoricheskoy nauki: uchebnoe posobie / V. A. El'chaninov. - Barnaul: Alt. gos. un-t, 1990. - 118 c.

10. Ivanova, N. I. Natsional'nye innovatsionnye sistemy /N. I. Ivanova. - M.: Nauka, 2002.- $244 \mathrm{~s}$.

11. Kapustina N.V., Kuznetsov Yu.V. Printsipy issledovaniya sistemy upravleniya riskami. Vestnik MGTU, tom 13, N 1, 2010 g. - S. 15-21

12. Korotkov, E. M. Issledovanie sistem upravleniya /E. M. Korotkov. - M.: DeKA, 2000. $-228 \mathrm{~s}$.

13. Kuznetsov, Yu.V. Razvitie metodologii menedzhmenta / Kuznetsov, Yu.V. // Problemy teorii i praktiki upravleniya. - 1997. - №4. - S. 110-114.

14. Kuznetsov, Yu.V. Teoriya organizatsii: uchebnoe posobie / Yu.V. Kuznetsov. - SPb.: Izd-vo Peterb. Un-ta, 2006. - 158 s.

15. Kuznetsov, Yu.V. Teoriya organizatsii: uchebnoe posobie / Yu.V. Kuznetsov. - SPb.: Izd-vo Peterb. Un-ta, 2006. - 158 s.

16. Malenkov, Yu. A. Sovremennyy menedzhment: posobie / Yu.A. Malenkov.- M.: ZAO Izd. «EKONOMIKA», 2010. - 439 s.

17. Matematika i kibernetika v ekonomike. Slovar'-spravochnik.-M.: «Ekonomika», 1975.

18. Nikolis,G.,Prigozhin,I. Poznanie slozhnogo. Vvedenie/ G.Nikolis,I. Prigozhin. - 2-e izd., per. s angl. - M.: URSS, 2003. - 275 s.

19. Parnyuk, M.A., Prichepiy, E.N., Kizima, V.V. Neobkhodimost' i sluchaynost' / M.A.Parnyuk, E.N. Prichepiy, V.V. Kizima.- Kiev: Nauk.dumka, 1988. - 310 s.s.109. 
20. Prangishvili, I. V., Pashchenko, F. F., Busygin, B. P. Sistemnye zakony i zakonomernosti $\mathrm{v}$ elektrodinamike, prirode, obshchestve / I.V.Prangishvili, F.F.Pashchenko,B. P. Busygin. - M.: Nauka, 2001. -125 s.

21. Prigozhin, I., Stengers, I. Poryadok iz khaosa: Novyy dialog cheloveka s prirodoy / I. Prigozhin, I.Stengers. M.: Progress, 1986. -432 s., s 386

22. Romanov, A.A. Ekonomicheskoe razvitie territorii / A.A. Romanov. - Krasnodar: YuIM, 2003. -42c.

23. Spitsnadel', V. N. Osnovy sistemnogo analiza: uchebnoe posobie / V. N. Spitsnadel'.SPb.: Bizness-pressa, 2000. - 326 s.

24. Fedosova R.N. Metodologicheskie osnovy upravleniya sotsial'no-ekonomicheskimi protsessami na predpriyatiyakh: monografiya.- Vladimir, VlGTU, 1996. - $176 \mathrm{~s}$.

25. Filimonova N.M. Strategiya razvitiya malogo predprinimatel'stva v Rossiyskoy Federatsii: monografiya / N.M. Filimonova. - Vladimir: VOOO VOI, 2005. - $250 \mathrm{s.}$

26. Shtoff, V. A. Problemy metodologii nauchnogo poznaniya/ V.A. Shtoff. - M.: Vysshaya shkola, 1978. - $271 \mathrm{c}$. 